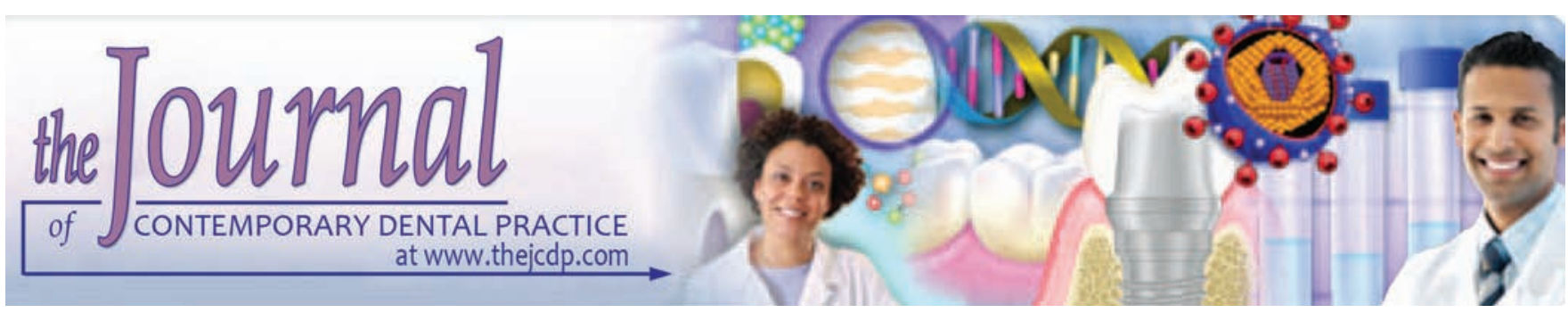

\title{
Measure and compare the Degree of Root Canal Transportation and Canal-centering ability of Twisted, ProTaper, and Conventional Stainless Steel K Files using Spiral Computed Tomography: An in vitro Study
}

${ }^{1}$ F Rejula, ${ }^{2}$ R Christalin, ${ }^{3}$ Waseem Ahmed, ${ }^{4}$ Shiji Dinakaran, ${ }^{5}$ Anupama S Gopinathan, ${ }^{6}$ Anulekh Babu

\begin{abstract}
Aim: The aim of this study was to compare canal transportation and centering ability of Twisted files (TF) and ProTaper (PT) files with conventional stainless steel (SS) $\mathrm{K}$ files.

Materials and methods: Thirty mandibular premolar teeth with root curvature of 25 to $35^{\circ}$ were selected. The samples were randomly divided into three groups of 10 each according to the type of files used for instrumentation. Group I was instrumented using TF, group II with PT files according to the manufacturer's recommendations, and group III with samples prepared with precurved SS K files using a step-back technique. After preparation, the samples were assessed using spiral computed tomography. Three sections were recorded at coronal, middle, and apical levels. Amount of transportation was assessed comparing with preinstrumentation images. Centering ability was calculated using Gambill's formula. The three groups were statistically compared using Student's t-test.
\end{abstract}

Results: Twisted files showed the least canal transportation and the best centering ability followed by PT file system. Stainless steel $\mathrm{K}$ files showed the highest transportation and least centering ability.

Conclusion: Twisted files showed the least amount of transportation and better centering compared with the other file systems.

Clinical significance: The study gives information of TF, a recently introduced rotary system (2008) with regard to its efficacy in preparing curved root canals. This study has shown that the centering ratio of rotary nickel titanium was better than that of SS files.

\footnotetext{
1,2Department of Conservative Dentistry and Endodontics Government Dental College, Thrissur, Kerala, India

${ }^{3}$ Department of Conservative Dentistry and Endodontics, Sree Sai Multispecialty Hospital, Belagavi, Karnataka, India

${ }^{4-6}$ Department of Conservative Dentistry and Endodontics Government Dental College, Trivandrum, Kerala, India

Corresponding Author: F Rejula, Department of Conservative Dentistry and Endodontics, Government Dental College Thrissur, Kerala, India, e-mail: rejula@hotmail.com
}

Keywords: Canal transportation, ProTaper files, Spiral computed tomography, Twisted files.

How to cite this article: Rejula F, Christalin R, Ahmed W, Dinakaran S, Gopinathan AS, Babu A. Measure and compare the Degree of Root Canal Transportation and Canalcentering ability of Twisted, ProTaper, and Conventional Stainless Steel K Files using Spiral Computed Tomography: An in vitro Study. J Contemp Dent Pract 2017;18(6):463-469.

Source of Support: Nil

Conflict of Interest: None

\section{INTRODUCTION}

Endodontics, as a specialty, has taken long strides since the indictment of William Hunter in 1910. We are now in an era where the exact cause of infection can be eliminated completely without sacrificing the tooth.

To debride the infected canal contents and radicular dentin, sufficient space has to be created to facilitate disinfection of the canal by irrigants and medicaments; these steps are referred to as "cleaning and shaping of root canal system".

Every root canal has its individual form, the apical part of curved canals being most challenging to prepare. As the curvature of canal space increases, it is progressively more difficult to maintain the original shape of the canal, especially near the apical foramen. ${ }^{1}$ The shaping process may result in various defects, such as ledges, zips, elbows, apical foramen, and canal transportation and in a worst case scenario strip perforations on the canal wall and perforations at the apical and furcation regions. ${ }^{2}$

The Glossary of Endodontic Terms (2003) defines transportation as "the removal of canal wall structure on the outside curve in the apical half of the canal due to the tendency of files to restore themselves to their original 
linear shape during canal preparation". ${ }^{3}$ This unidirectional removal of dentin will result in some unprepared areas, thereby favoring the presence of necrotic debris, compromising the apical seal during obturation.

Several methodologies have been proposed to evaluate instrumentation, which involves plastic models, histological sections, scanning electron microscopy, serial sectioning, and silicone impressions. Sectioning is the most accurate method but it is invasive and restricts the study as the tooth is destroyed and is time consuming. Computed tomography (CT) has proven to be a reproducible, noninvasive experimental tool of evaluating changes within root canal system ${ }^{4}$ and is shown to be an accurate method for evaluating transportation. ${ }^{5}$

The stainless steel (SS) K files have been the principal instruments to prepare the root canals, but a major limiting factor when dealing with curved canals has been excessive stiffness of the larger file sizes which produce distortion or straightening of the canal.

The introduction of instruments fabricated from nickel titanium (NiTi) has significantly improved the quality of root canal shaping greatly, because of their increased flexibility as compared with their SS counterparts. Moreover, in the past few years, important modifications to rotary instruments have been proposed to increase their reliability and effectiveness in controlling the preparation of curved canals. This trend has led to introduction of a plethora of NiTi instruments available, which are of varying designs and nonstandard tapers, making it more difficult to select.

The ProTaper (PT) instrument system designed by Dr Clifford Ruddle, Dr John West, and Dr Pierre Machtou is a unique concept of varying tapers along instrument's long axis and are supplied as two Shaper and three Finisher file system.

In 2008, Twisted File (TF) was introduced by SybronEndo, which is the first of its kind of files to be manufactured by twisting, a process similar to that of twisting SS K files rather than the usual grinding of NiTi alloys. ${ }^{6}$ These TF as claimed by the manufacturer have certain features like R-phase heat treatment and special surface conditioning which increases its flexibility.

Consequently, this study was undertaken to investigate the shaping abilities of two NiTi systems: PT file and TF and conventional SS K files by evaluating two parameters: Canal transportation and canal-centering ability using spiral CT as an experimental tool.

\section{MATERIALS AND METHODS}

Occupational Safety and Health Administration and the Centre for Disease Control and Prevention recommendations and guidelines were followed for collection, storage, sterilization, and handling of the extracted teeth and stored in $5.25 \%$ sodium hypochlorite.
Sample consisted of 30 decoronated single-rooted curved mandibular premolar teeth with 25 to $35^{\circ}$ root curvature. A digital radiograph was taken with $60 \mathrm{kV}$ and $0.2 \mathrm{~ms}$ exposure to determine the root canal curvature, keeping an ISO \# $10 \mathrm{~K}$ files $0.5 \mathrm{~mm}$ short of working length inside the root canal. These digital radiographs were then transferred to a personal computer in the form of JPEG images and opened in Adobe Photoshop CS5, and straight lines were traced along the long axis of the file and angulations determined according to the procedure recommended by Schneider.?

Access cavity was prepared using a \#4 carbide bur (Dentsply Maillefer) under water spray. A size 10 SS K file was placed into the canal until it was visualized at the apical foramen and working length was established 0.5 $\mathrm{mm}$ short of apex. For more uniform samples, the teeth were decoronated $18 \mathrm{~mm}$ from the apex using a diamond disk in a micromotor straight handpiece.

Prepared root samples were embedded in clear acrylic after keeping them in a metal mold. The teeth were then randomly divided into three experimental groups as follows:

Group I: TF group $(\mathrm{n}=10)$

Group II: PT file group $(\mathrm{n}=10)$

Group III: SS K file group $(\mathrm{n}=10)$

All teeth were scanned by spiral CT (high performance 64-slice CT scanner Optima 660CT GE, Munich, Germany) at $120 \mathrm{kV}$ and $230 \mathrm{~mA}$, to determine the root canal shape before instrumentation. The sections taken were of $0.6 \mathrm{~mm}$ thickness. Three sections from each tooth were studied; the number of the tooth and its level were archived on the hard disk of the computer. The first section was taken $3 \mathrm{~mm}$ from the apical end of the root (apical level, Fig. 1A) and second section $9 \mathrm{~mm}$ from the apex (Fig. 2A). The third section at the cervical level ( $3 \mathrm{~mm}$ below the orifice from the coronal level, Fig. 3A) was recorded. All root canals were instrumented to the working length with sizes 10 and 15 size $K$ files by using a step-back technique. Canals larger than ISO size 15 files were discarded since the master apical file was limited at size \# 25.

Group I teeth were prepared by using TF instruments at the required speed of $500 \mathrm{rpm}$. The shaping procedure commenced with TF size 25 taper 0.08 . The coronal aspect of the root canal was shaped with 0.08 taper till the level of passive penetration. Twisted file size 25 taper 0.06 was inserted and used until it was $2 \mathrm{~mm}$ short of working length. Then, shaping was continued with TF size 25 taper 0.04 followed by taper 0.06 and then taper 0.08 to working length.

Group II samples were prepared by PT system according to the manufacturer's recommendations. The shaping 


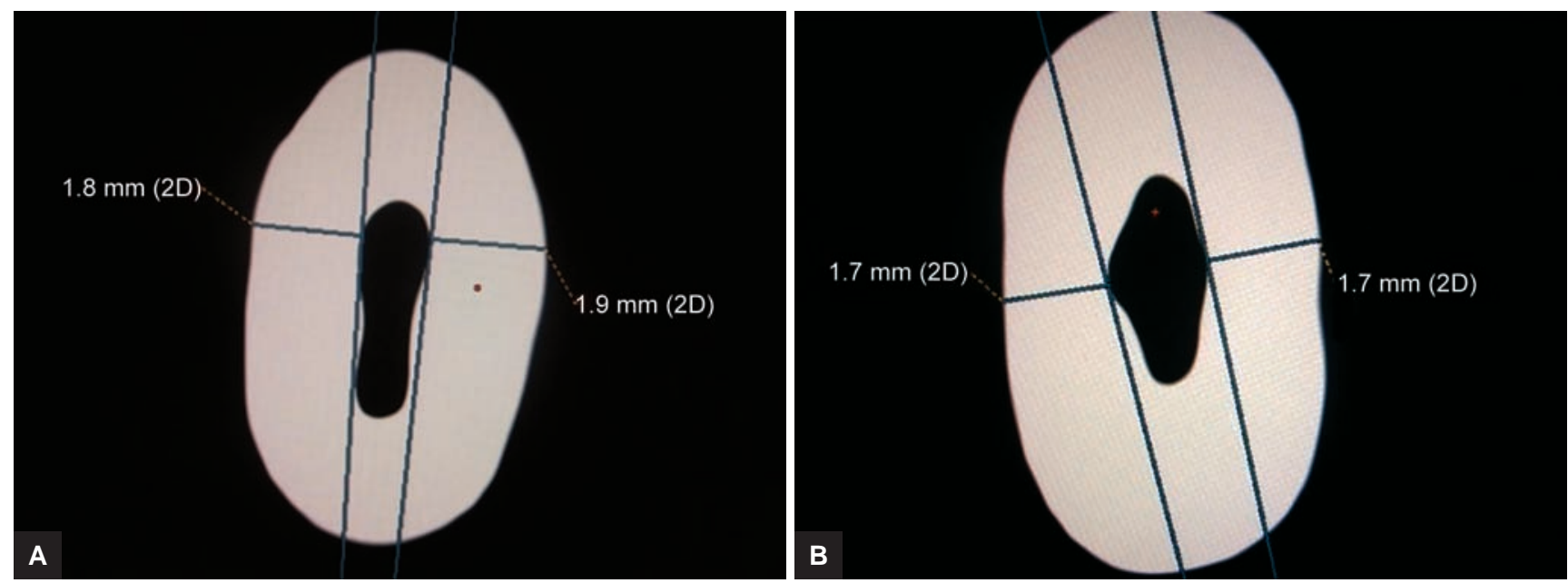

Figs $1 \mathrm{~A}$ and $\mathrm{B}$ : Cervical section at $3 \mathrm{~mm}$
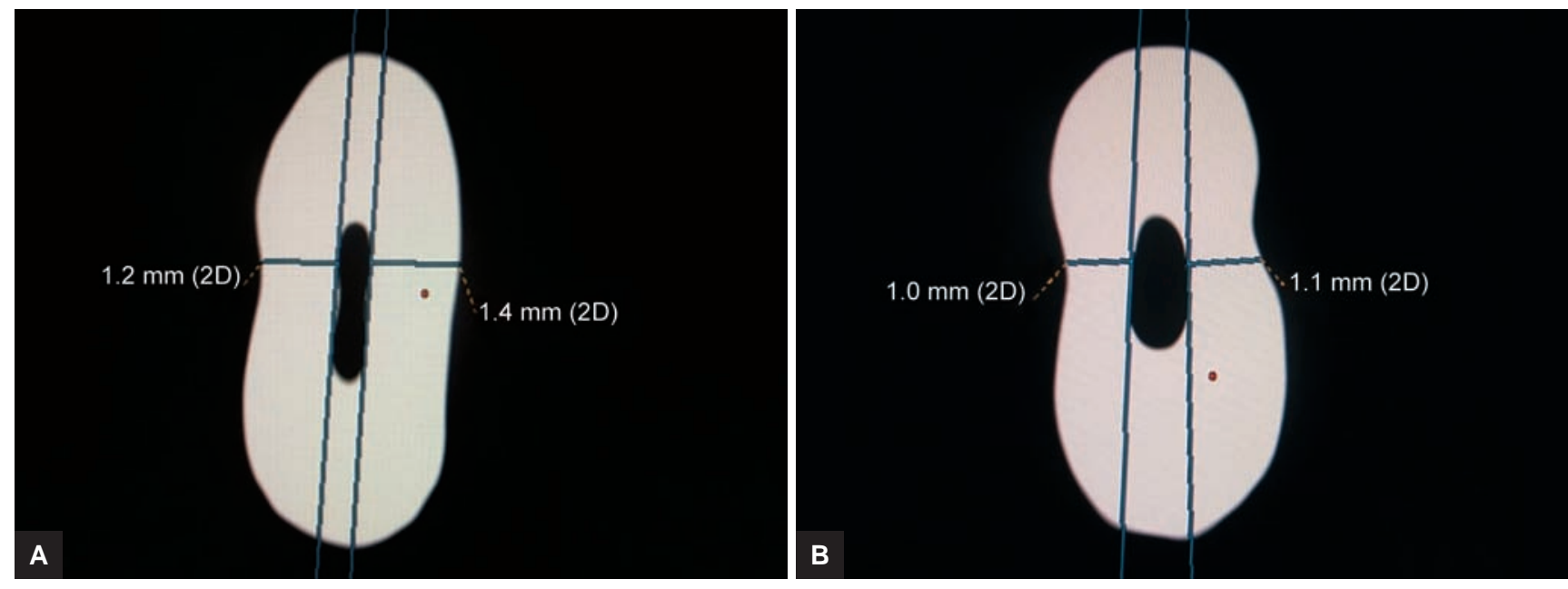

Figs $2 \mathrm{~A}$ and $\mathrm{B}$ : Middle section at $9 \mathrm{~mm}$

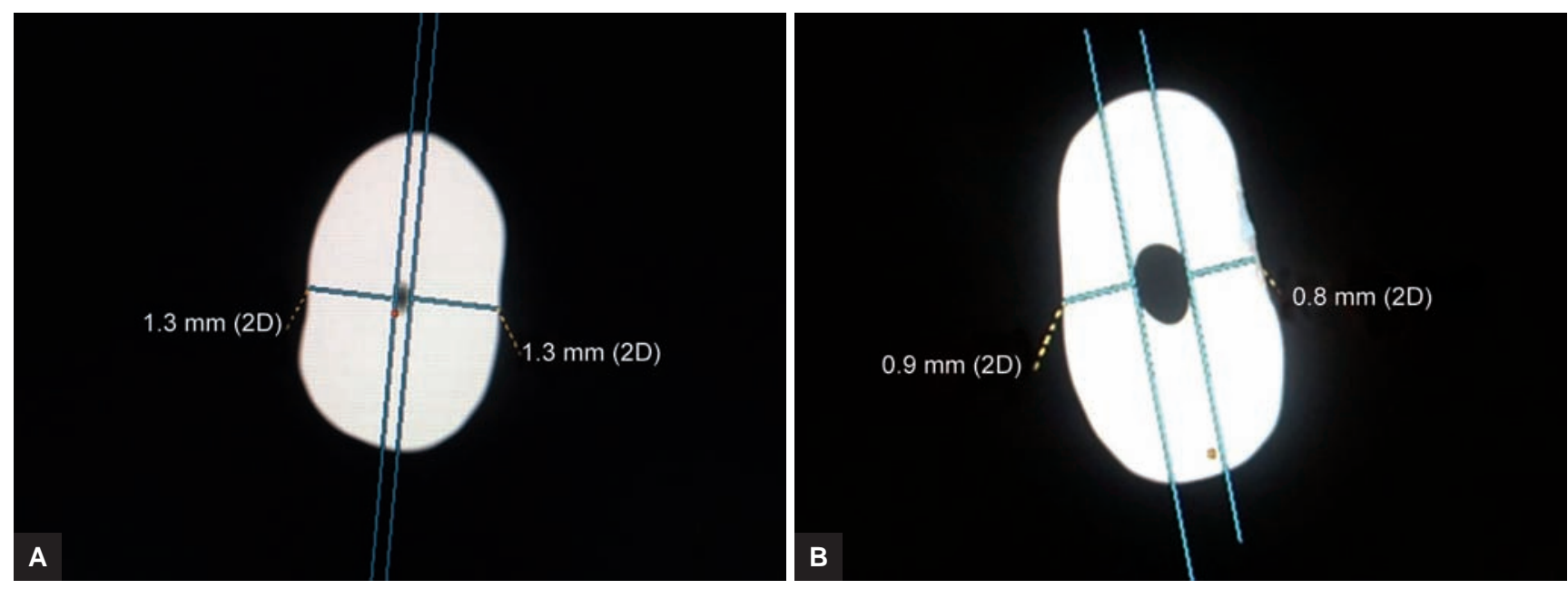

Figs $3 \mathrm{~A}$ and $\mathrm{B}$ : Apical section at $3 \mathrm{~mm}$ from the apex

procedure commenced with PT S1 and then S2 to the established working length using a brushing motion. Shaping continued with F1 finishing instrument followed by F2 to working length; finishing files were used passively and withdrawn from the root canal as soon as they reached the working length for one time.
After the preparation, all samples in both groups had standardized apical preparation of 0.08 taper size 25 .

The samples in group III were prepared using precurved SS K files in quarter-turn pull motion using a step-back technique. After preparation, the final apical size was standardized at size 25 ( $20-40 \mathrm{~K}$ file). 
For all groups after the use of each file, canals were irrigated with $3 \mathrm{~mL}$ of a $5.25 \% \mathrm{NaOCl}$ solution followed by normal saline. Ethylenediaminetetraacetic acid (EDTA) was used as a lubricant during instrumentation and when root canal instrumentation was completed, $1 \mathrm{~mL}$ of $17 \%$ EDTA was used for 1 minute followed by $3 \mathrm{~mL}$ of $\mathrm{NaOCl}$ and a final flush of saline solution. Each instrument was changed after five canals.

All these prepared teeth samples were then subjected to spiral CT under identical conditions as in the preinstrumentation samples; the images were recorded and archived for further evaluation (Figs 1B, 2B and 3B).

Images were then transferred to the computer (GE Centricity DICOM viewer), and the shortest distance from the root canal to the mesial and distal wall was measured and recorded (Fig. 4). Similar measurements were taken postinstrumentation at the same levels as in the preinstrumentation slices. Canal transportation and centering ability were calculated based on the formula put forth by Gambill et al. ${ }^{4}$

The data were tabulated using Microsoft Excel 2007 and analyzed using Statistical Package for Social Sciences version 11.0 software, and results were analyzed using Student's t-test.

Transportation results give an indication of how much material was removed with respect to the ideal preparation (where no transportation occurs). Centering ability indicates how well a technique removed dentin equally over the prepared area.
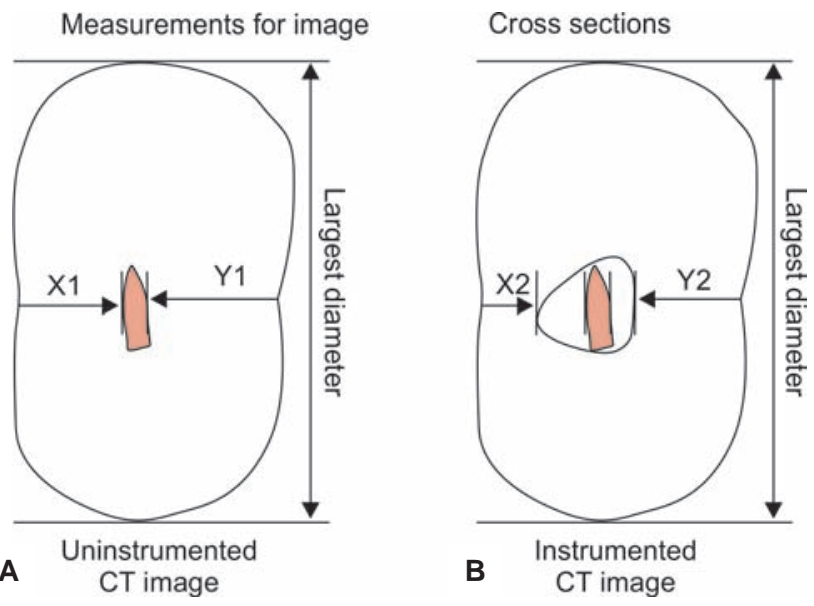

Figs 4A and B: Representative drawing of the spiral CT image. Uninstrumented CT image: Shaded area shows the original canal space. Instrumented CT image, light shaded area enveloping the darker area depicts the altered morphology postinstrumentation. ${ }^{4}$ $\mathrm{X} 1$ : Shortest distance from outside of the root to the periphery of the uninstrumented root canal $(A)$. $Y 1$ : Shortest distance from outside of the root to the periphery of the uninstrumented root canal on the opposite side (A). X2: Shortest distance from outside of the root to the periphery of the instrumented root canal (B). Y2: Shortest distance from outside of the root to the periphery of the uninstrumented root canal on the opposite side (B)
The formula to measure transportation is:

$$
[(\mathrm{X} 1-\mathrm{X} 2)-(\mathrm{Y} 1-\mathrm{Y} 2)]
$$

While assessing the transportation, a value other than " 0 " indicates that some transportation has occurred. Centering ability for each section was calculated for each section using the following ratio.

$$
\frac{(\mathrm{X} 1-\mathrm{X} 2)}{(\mathrm{Y} 1-\mathrm{Y} 2)} \text { or } \frac{(\mathrm{Y} 1-\mathrm{Y} 2)}{(\mathrm{X} 1-\mathrm{X} 2)}
$$

While calculating the centering ratio by the formula using pre- and postinstrumentation values, the smallest value has to be the numerator always. A value of " 1 " indicates perfect centering.

\section{RESULTS}

\section{Canal Transportation}

Table 1 compares mean canal transportation of TF, PT, and SS K files in the cervical area. The canal transportation of cervical area in increasing order of severity can be written as TF, PT, followed by SS files. There was a statistically significant difference for TF when compared with both PT and SS files ( $p$-value 0.022 and 0.000 respectively). The difference between PT and SS was statistically significant $(\mathrm{p}=0.000)$.

Table 2 compares mean canal transportation of TF, PT, and SS files in the middle third area. The canal transportation of middle third area in ascending order can be written as TF, PT, followed by SS files (mean 0.03, 0.04, 0.07 respectively), but there was no statistically significant difference among groups. The transportation of TF and PT was almost similar.

Table 3 compares mean canal transportation of TF, PT, and SS files in the apical third area of the root canal. The canal transportation of apical third area was statistically significant for TF compared with PT files and SS files ( $p=0.026$ and 0.000 respectively). PT files compared with SS showed significant difference, with transportation being maximum for SS files $(p=0.000)$.

Table 1: Comparison of transportation (cervical) in millimeters

\begin{tabular}{lrllll}
\hline Groups & Mean $\pm S D$ & $n$ & Pair & T-value & $p$-value \\
\hline I & $0.07 \pm 0.13$ & 10 & Groups I and II & $2.51^{*}$ & 0.022 \\
II & $0.29 \pm 0.24$ & 10 & Groups I and III & $14.01^{* *}$ & 0.0001 \\
III & $-1.04 \pm 0.21$ & 10 & Groups II and III & $13.06^{* *}$ & 0.0001
\end{tabular}

SD: Standard deviation; *significant at 0.05 level; ** significant at 0.01 level

Table 2: Comparison of transportation (middle) in millimeters

\begin{tabular}{lrllll}
\hline Groups & Mean \pm SD & $n$ & Pair & T-value & $p$-value \\
\hline I & $0.03 \pm 0.23$ & 10 & Groups I and II & 0.62 & 0.543 \\
II & $-0.04 \pm 0.27$ & 10 & Groups I and III & 0.83 & 0.417 \\
III & $-0.07 \pm 0.30$ & 10 & Groups II and III & 0.23 & 0.818 \\
\hline
\end{tabular}

SD: Standard deviation 
Measure and Compare the Degree of Root Canal Transportation and Canal-centering Ability of Twisted, ProTaper

Table 3: Comparison of transportation (apical) in millimeters

\begin{tabular}{lrllll}
\hline Groups & Mean \pm SD & $n$ & Pair & T-value & $p$-value \\
\hline I & $-0.03 \pm 0.17$ & 10 & Groups I and II & $2.42^{*}$ & 0.026 \\
II & $0.31 \pm 0.41$ & 10 & Groups I and III & $14.12^{* *}$ & 0.0001 \\
III & $-1.15 \pm 0.18$ & 10 & Groups II and III & $10.28^{* *}$ & 0.0001
\end{tabular}

SD: Standard deviation; *significant at 0.05 level; ** significant at 0.01 level

Table 5: Comparison of centering ability (middle)

\begin{tabular}{llllll}
\hline Group & Mean \pm SD & $n$ & Pair & T-value & $p$-value \\
\hline I & $0.69 \pm 0.16$ & 10 & Groups I and II & 0.5 & 0.058 \\
II & $0.64 \pm 0.25$ & 10 & Groups I and III & 2.02 & 0.622 \\
III & $0.47 \pm 0.30$ & 10 & Groups II and III & 1.38 & 0.184 \\
\hline
\end{tabular}

SD: Standard deviation

\section{Centering Ratio}

Table 4 compares mean canal-centering ability of TF, PT, and SS files in the cervical third area. The canalcentering ability of different files in cervical region can be written in descending order as TF, PT, followed by SS files (mean values $0.74,0.41,0.21$ respectively). The difference between TF and PT was statistically significant $(p=0.000)$. Likewise, there was statistically significant difference between SS files when compared with TF and PT groups ( $\mathrm{p}=0.000$ and 0.007 respectively).

Table 5 compares mean canal-centering ability of $\mathrm{TF}, \mathrm{PT}$, and SS files in the middle third area. The canalcentering ability of different files in middle region can be written in descending order as TF, PT, followed by SS files (mean values $0.69,0.64,0.47$ respectively), but the difference among them was not significant statistically ( $p=0.058,0.622,0.184$ respectively).

Table 6 compares mean canal-centering ability of $\mathrm{TF}, \mathrm{PT}$, and SS files in the apical third area. The canalcentering ability of different files in apical region can be written in descending order as TF, PT followed by SS files (mean values $0.82,0.25,0.10$ respectively). Twisted file having statistically significant difference in canalcentering ability when compared with both PT and SS files ( $\mathrm{p}=0.000$ and 0.000 respectively) and the difference between PT and SS was also significant $(\mathrm{p}=0.025)$.

\section{DISCUSSION}

The most important stage in root canal treatment is cleaning and shaping along with maintenance of canal curvature and creation of a funnel-shaped canal form with the smallest diameter at the apex. A number of procedural errors, such as zip, perforation, ledge formation, apical transportation, or deviation from the original canal pathway ${ }^{2}$ can occur when shaping curved canals.

This study was designed to determine the canal transportation and the centering ability of two NiTi rotary
Table 4: Comparison of centering ability (cervical)

\begin{tabular}{llllll}
\hline Group & Mean \pm SD & $n$ & Pair & T-value & $p$-value \\
\hline I & $0.74 \pm 0.13$ & 10 & Groups I and II & $4.6^{*}$ & 0.0001 \\
II & $0.41 \pm 0.19$ & 10 & Groups I and III & $11.12^{*}$ & 0.0001 \\
III & $0.21 \pm 0.08$ & 10 & Groups II and III & $3.07^{*}$ & 0.007
\end{tabular}

SD: Standard deviation; *significant at 0.01 level

Table 6: Comparison of centering ability (apical)

\begin{tabular}{llllll}
\hline Groups & Mean $\pm S D$ & $n$ & Pair & $t$-value & $p$-value \\
\hline I & $0.82 \pm 0.19$ & 10 & Groups I and II & $6.88^{*}$ & 0.0001 \\
II & $0.25 \pm 0.18$ & 10 & Groups I and III & $11.77^{*}$ & 0.0001 \\
III & $0.10 \pm 0.04$ & 10 & Groups II and III & $2.44^{* *}$ & 0.025 \\
\hline
\end{tabular}

SD: Standard deviation; *significant at 0.01 level; ${ }^{* *}$ significant at 0.05 level

systems, PT and TF with SS K files using spiral CT as an experimental tool.

The TF is a recently introduced rotary system (2008), and very little information is available with regard to its efficacy in preparing curved root canals. This file system is available in only one tip size ISO \# 25 but in varying tapers of $4,6,8,10$, and 12 . According to the manufacturer, it is a watershed invention, where the NiTi is not ground to create the cutting edges but is twisted in $\mathrm{R}$ phase of heat treatment to give the form of a file. This avoids generation of microcracks. Moreover, it is made from one piece of NiTi, hence enhanced structural integrity and reduced "wobble" are added features compared with other file systems. ${ }^{8}$

The PT file system was selected because of its variable taper design along its long axis. The PT instruments were designed "to cover the whole range of treatment with only a few files, which incorporate superior flexibility, unmatched efficiency, and improved safety". ${ }^{9}$ Its design evolved based on Schilder's principles of canal preparation. To optimize safety, these files are allowed to float in the canal and follow the glide path and used as a brush laterally to selectively cut dentin on outstroke. ${ }^{10}$ The SS K files were selected for this study because these files have been traditionally used for preparing root canals. If precurved and used, it allows greater control of file direction, which increases safety by preserving critical areas when compared with the oscillatory technique. ${ }^{11}$ Premolars extracted for orthodontic reasons were selected in the present study because they usually present accentuated curvatures and mesiodistal flattening, which present as challenges during chemomechanical instrumentation.

A whole range of methods are available to evaluate transportation, such as the Bramante serial sectioning technique, simulated root canals, radiographic assessment, and micro CT. All these methods have disadvantages, such as loss of some part of the specimen, not reflect the clinical situation, and highly subjective in assessment. Micro-CT 
provides three-dimensional reconstruction images and accuracy but is expensive and time consuming. Spiral $\mathrm{CT}$, on the other hand, results in accurate and comparable results before and after instrumentation. It is also relatively faster and inexpensive in generating images.

Present investigation corroborates the findings of a great deal of previous work on NiTi instruments, where they maintained the original canal shape even in extremely curved canals. ${ }^{12,13}$ When compared with SS K files, the NiTi instruments remained well centered in confirmation with the findings of Luiten et $\mathrm{al}^{14}$ and Glossen et al. ${ }^{12}$

When comparing the shaping abilities of different root canal instruments, it is of importance to have similar apical preparation diameters. ${ }^{15}$

To maintain uniform apical preparations, samples prepared with PT group were limited at F2, while in the SS K file group the master apical file was \#25 size K file, after which the canal preparations were carried out in a step-back fashion (20-40 size) precurved with periodic recapitulations to maintain apical patency.

In this study, the TF produced the least amount of transportation and provided better centering at the apical third with a mean transportation of $0.03 \pm 0.17 \mathrm{~mm}$ and mean centering ratio of $0.82 \pm 0.19$, which is consistent with the findings of Gergi et $\mathrm{al}^{16}$ and Hashem et al. ${ }^{17}$ This might be attributed to the new manufacturing method compared with other rotary NiTi files.

There was a statistically significant difference between all study groups at the apical levels while comparing transportation and centering. Maximum transportation occurred in the SS K files $\rightarrow \mathrm{PT} \rightarrow \mathrm{TF}$ in that order. This is in accordance with earlier studies, ${ }^{18-21}$ while centering ability for the TF was significantly better than the PT followed by SS K files in apical third.

Transportation due to the SS K files was significantly more than the two rotary NiTi file systems, confirming with the studies carried out by Glossen et $\mathrm{al}^{12}$ and Gambill et al. ${ }^{4}$ This may have been due to the more aggressive cutting action, less flexibility, and marked degree of straightening. Moreover, the SS files above the size \#15 and \#20 are relatively stiff.

In this study, PT file system showed statistically significant difference concerning both parameters when compared with other groups. This may be due to more aggressive cutting action by engaging small portion of dentin at a time. ${ }^{9}$ Moreover, when F3 is taken to working length, it behaves like a $0.04 / \# 45$ file at the apical third of the canal. Furthermore, the variable tapers along the length of the file reach up to $12 \%$ increase in taper per $\mathrm{mm}$ in $\mathrm{D} 16$ portion of the file. ${ }^{18}$

Transportation in the middle third by TF and PT file was comparable although the PT file had a slightly higher amount of transportation. This might be attributed to the higher taper and thickness of PT system compared with other rotary systems at the same level. This creates more inner widening of the canal and resultant decrease in canal curvature. In addition, there is an absolute necessity to enlarge a curve with PT instruments because the larger instruments are stiffer and cause high lateral forces in curved canals. These restoring forces attempt to return the file to its original shape and act on the outer side of the canal wall during preparation leading to a loss of centering within the PT system. ${ }^{18}$

The SS files produced maximum amount of transportation in middle third, in confirmation with Gambill et $\mathrm{al}^{4}$ and Glossen et al. ${ }^{12}$ This may be due to their unyielding nature. This demonstrates that NiTi files decrease the risk of strip perforations and danger zones in curved canals.

The TF with a mean transportation of $0.07 \pm 0.13$ was followed by PT files, which showed a value of $0.29 \pm 0.24$, while the SS K files had a mean transportation value of $-1.04 \pm 0.21$ (Table 1).

These results are in confirmation with the previous studies of Gergi et $\mathrm{al}^{16}$ and Hashem et al. ${ }^{17}$ The lesser amount of transportation with the TF may be attributed to the proprietary manufacturing procedure, which provides these files with increased flexibility enabling them to negotiate extremely curved canals. ${ }^{18}$

It should be noted that the worst centering ratio at the coronal level was observed with SS K files, which are inherently stiff followed by the PT which have a marked transition in tapers along their lengths. Furthermore, there is a transition between S2 and F1 files. The F2 files are stiffer compared with other NiTi file systems.

The TF system provided the best centering ratio, which was significant compared with the other two file systems, confirming the observations of other studies by Gergi et $\mathrm{al}^{16}$ and El Batouty and Elmallah. ${ }^{22}$

Transportation results give an indication of how much material was removed with respect to the ideal preparation (where no transportation occurs). Centering ability indicates how well a technique removed dentin equally over the prepared area. The relevance of canal centering during instrumentation pertains primarily to canal transportation. $3,23,24$

\section{CONCLUSION}

According to the methodology implemented and the obtained results, the following conclusions can be made:

- None of the systems used in the study had perfect centering. Twisted file showed good centering ability while SS K files had poor centering ability. The good centering ability at the apical level in TF system implies that dentin was removed in a more uniform pattern. 
- All techniques produced canal transportation with $\mathrm{K}$ files, producing the maximum transportation and $\mathrm{TF}$ the least.

Although not tested in this study, this would suggest that the debridement of an infected canal may be adequately accomplished by TF and PT files.

Within the limitations of this study, TF showed the least canal transportation and the best centering ability followed by PT file system. Stainless steel K files showed the highest transportation and least centering ability.

\section{REFERENCES}

1. Cailleteau JG, Mullaney TP. Prevalence of teaching apical patency and various instrumentation and obturation techniques in United States dental schools. J Endod 1997 Jun;23(6):394-396.

2. Schilder H. Cleaning and shaping the root canal. Dent Clin North Am 1974 Apr;18(2):269-296.

3. Weine, FS.; Lio, PJ. Endodontic therapy. 3rd ed. St Louis: CV Mosby; 1982.

4. Gambill JM, Alder M, del Rio CE. Comparison of nickeltitanium and stainless steel hand-file instrumentation using computed tomography. J Endod 1996 Jul;22(7):369-375.

5. Nielsen RB, Alyassin AM, Peters DD, Carnes DL, Lancaster J. Microcomputed tomography: an advanced system for detailed endodontic research. J Endod 1995 Nov;21(11):561-568.

6. Peters, OA.; Peters, CI. Cleaning and shaping of the root canal system. In: Hargreaves K, Cohen S, editors. Pathways of the Pulp. 10th ed. St Louis: Elsevier; 2011. p. 304.

7. Schneider SW. A comparison of canal preparations in straight and curved root canals. Oral Surg Oral Med Oral Pathol 1971 Aug;32(2):271-275.

8. Mounce RE. Rotary nickel titanium instrumentation revolutionized: The twisted file. Oral Health 2008;5:6-9.

9. Ruddle CJ. The ProTaper advantage: shaping the future of endodontics. Dent Today 2001 Oct;3:1-9.

10. Ruddle CJ. The ProTaper technique. Endod Top 2005 Mar;10:187-190.

11. Hülsmann M, Peters OA, Dummer PMH. Mechanical preparation of root canals: shaping goals, techniques and means. Endod Top 2005 Mar;10(1):30-76.

12. Glossen CR, Haller RH, Dove SB, del Rio CE. A comparison of root canal preparations using $\mathrm{Ni}-\mathrm{Ti}$ hand, $\mathrm{Ni}-\mathrm{Ti}$ engine-driven, and K-flex endodontic instruments. J Endod 1995 Mar;21(3):146-151.

13. Short JA, Morgan LA, Baumgartner JC. A comparison of canal centering ability of four instrumentation techniques. J Endod 1997 Aug;23:503-507.

14. Luiten DJ, Morgan LA, Baugartner JC, Marshall JG. A comparison of four instrumentation techniques on apical canal transportation. J Endod 1995 Jan;21(1):26-32.

15. Bergmans L, Van Cleynenbreugel J, Beullens M, Wevers M, Van Meerbeek B, Lambrechts P. Progressive vs constant tapered shaft design using NiTi rotary instruments. Int Endod J 2003 Apr;36(4):288-295.

16. Gergi R, Rjeily JA, Sader J, Naaman A. Comparison of canal transportation and centering ability of twisted files, PathfileProTaper system, and stainless steel hand K-files by using computed tomography. J Endod 2010 May;36(5):904-907.

17. Hashem AA, Ghoneim AG, Lutfy RA, Foda MY, Omar GA. Geometric analysis of root canals prepared by four rotary NiTi shaping systems. J Endod 2012 Jul;38(7):996-1000.

18. Schäfer E, Vlassis M. Comparative investigation of two rotary nickel-titanium instruments: ProTaper vs RaCe. Part 2. Cleaning effectiveness and shaping ability in severely curved root canals of extracted teeth. Int Endod J 2004 Apr;37(4):239-248.

19. Yun HH, Kim SK. A comparison of the shaping abilities of 4 nickel-titanium rotary instruments in simulated root canals. Oral Surg Oral Med Oral Pathol Oral Radiol Endod 2003 Feb;95(2):228-233.

20. Javaheri HH, Javaheri GH. A comparison of three Ni-Ti rotary instruments in apical transportation. J Endod 2007 Mar;33(3):284-286.

21. Iqbal MK, Firic S, Tulcan J, Karabucak B, Kim S. Comparison of apical transportation between ProFile and ProTaper NiTi rotary instruments. Int Endod J 2004 May;37(6):359-364.

22. El Batouty KM, Elmallah WE. Comparison of canal transportation and changes in canal curvature of two nickel-titanium rotary instruments. J Endod 2011 Sep;37(9):1290-1292.

23. Knowles KI, Ibarrola JL, Christiansen RK. Assessing apical deformation and transportation following the use of LightSpeed root-canal instruments. Int Endod J 1996 Mar;29(2):113-117.

24. Dhingra A, Mangat P, Miglani A, Kalkhande S, Bhullar HK. To evaluate the effect of two passive ultrasonic irrigation methods on removal of dentin debris from root canal systems using computational fluid dynamics study model. Int J Contemp Dent Med Rev 2014 Dec;2014:7. 